\title{
Iron chelation by curcumin suppresses both curcumin-induced autophagy and cell death together with iron overload neoplastic transformation
}

\author{
Nathan E. Rainey ${ }^{1,2,6}$, Aoula Moustapha ${ }^{1}$, Ana Saric ${ }^{1,3}$, Gael Nicolas ${ }^{4}$, Franck Sureau ${ }^{5}$ and Patrice X. Petit ${ }^{1}$
}

\begin{abstract}
Iron overload, notably caused by hereditary hemochromatosis, is an excess storage of iron in various organs that causes tissue damage and may promote tumorigenesis. To manage that disorder, free iron depletion can be induced by iron chelators like deferoxamine that are of increasing interest also in the cancer field since iron stock could be a potent target for managing tumorigenesis. Curcumin, a well-known active substance extracted from the turmeric rhizome, destabilizes endoplasmic reticulum, and secondarily lysosomes, thereby increasing mitophagy/autophagy and subsequent apoptosis. Recent findings show that cells treated with curcumin also exhibit a decrease in ferritin, which is consistent with its chemical structure and iron chelating activity. Here we investigated how curcumin influences the intracellular effects of iron overload via Fe-nitriloacetic acid or ferric ammonium citrate loading in Huh-7 cells and explored the consequences in terms of antioxidant activity, autophagy, and apoptotic signal transduction. In experiments with T51B and RL-34 epithelial cells, we have found evidence that curcumin-iron complexation abolishes both curcumin-induced autophagy and apoptosis, together with the tumorigenic action of iron overload.
\end{abstract}

\section{Introduction}

Iron is a key element of numerous biological processes, but the presence of free or loosely bound iron can be toxic to cells ${ }^{1}$. Iron being an active redox metal, the excess free form can generate reactive oxygen species (ROS) through Haber-Weiss reduction followed by Fenton reactions ${ }^{2,3}$. The liver plays a major role in regulating iron storage in the case of excess iron or iron uptake in the case of deficiency. Aberrant iron accumulation can lead to cirrhosis and hepatocarcinoma, but also to heart damage, joint, and metabolic disorders ${ }^{4,5}$. Phlebotomy remains the

\footnotetext{
Correspondence: Patrice X. Petit (patrice.petit@inserm.fr)

${ }^{1}$ CNRS UMR 8003, SSPIN Saints-Pères Neurosciences Institute, Paris University, Saint-Germain Campus, 45 rue des Saints-Pères, 75006 Paris, France ${ }^{2}$ INSERM U1148, Laboratory for Vascular Translational Science, UFR SMBH, Université Paris 13, Sorbonne Paris Cité, F-93017 Bobigny, France Full list of author information is available at the end of the article. These authors contributed equally: Nathan E. Rainey, Aoula Moustapha Edited by I. Lavrik
}

mainstay of iron-overload diseases, but iron chelation therapy has proven to be a valuable alternative ${ }^{6}$.

Although iron chelation therapy was initially designed to alleviate the toxic effects of excess iron occurring in iron-overload diseases, the novel toxicological properties of some iron chelator complexes have radically shifted their intended applications toward cancer chemotherapy $^{7-9}$. Some iron chelators are able not only to chelate iron, but also to inhibit the redox properties of free labile iron. Such ligands may prevent iron from participating in Fenton reactions, inhibiting the formation of ROS like the hydroxyl radical, which initiates oxidative damage ${ }^{10}$ and also ferroptosis, recently recognized as a form of regulated necrotic cell death ${ }^{11}$. Ferroptosis is usually designed as one of the multiple variants of cell death that can be characterized by a high intracellular level of free iron associated with $\operatorname{ROS}^{12,13}$. Ferroptosis is linked to the production of reduced glutathione and/or to alterations of 
glutathione peroxidase 4 (GPX4), which usually acts as a ROS controller ${ }^{14-16}$. Additive markers of ferroptosis are lipid peroxidation and protein carbonylation leading to more ROS and death signaling ${ }^{10,17}$. Interestingly, some genetic disorders of iron metabolism and/or chronic inflammation often progress to iron overload and recent evidence shows, for example, the possibility of lowering brain iron accumulation with the membrane permeant chelator deferiprone in Friedreich ataxia ${ }^{18-21}$.

However, the choice of iron chelators is critical. Normally, the chelation of excess iron gives rise to a more inactive complex, hence providing a useful method of preventing the toxic effects of iron-overload diseases. In contrast, some chelators enhance the production of ROS after complexation with $\mathrm{Fe}^{2+}$. These chelators may induce $\mathrm{Fe}^{2+}$ toxicity of interest in cancer chemotherapy ${ }^{22,23}$. By rapidly depleting proliferating cancer cells of $\mathrm{Fe}^{2+}$, iron chelators can also inhibit the activity of Fe that acts as coenzyme to essential steps of DNA synthesis ${ }^{24-26}$. In addition, $\mathrm{Fe}^{2+}$ depletion is known to affect the expression of molecules involved in cell cycle progression and growth, i.e. $\mathrm{N}$-myc downstream regulated gene 1, cyclin $\mathrm{D} 1$, cyclin $\mathrm{A}$ and $\mathrm{p} 21^{\text {waf1 }}$ leading to G1/S arrest in the cell cycle $^{27-29}$. These effects combined with ROS generation provide multiple mechanisms of action mediated by $\mathrm{Fe}^{2+}$ chelation to inhibit tumor growth.

Curcumin is the major chemical component of turmeric, a dietary spice made from the root of Curcuma longa $L$., which is used extensively in traditional Indian medicine ${ }^{30}$. Curcumin is a potent bioactive compound that is the subject of active study in the fields of cancer ${ }^{31-33}$, atherosclerosis $^{34}$, steatohepatitis ${ }^{35}$, and neurodegenerative diseases, such as Alzheimer's disease $\mathrm{e}^{36,37}$ and Parkinson's disease $^{38,39}$, as well as for the promotion of wound healing $^{40-42}$.

At the cellular level, curcumin's mechanisms of action are complex and multifactorial. We and others have previously addressed its mode of action and confirmed its hormetic nature ${ }^{43-47}$. At low concentration, curcumin has a very effective antioxidant activity, whereas at higher concentration $(\geq 20 \mu \mathrm{M})$ it behaves as a potent pro-oxidant ${ }^{47}$.

In the field of cancer, curcumin inhibits the proliferation of tumor cells in vitro and in vivo. It also inhibits cell invasion, arrests cancer cells at the G2/M phase of the cell cycle, and induces autophagy. Furthermore, curcumin suppresses the activation of AKT, mTOR and P70S6K proteins ${ }^{46,48,49}$. Curcumin, therefore, is a potent tumor suppressor and simultaneously an inducer of autophagy. In the case of failure, this sequence of events leads to apoptosis $^{44}$. Taken together, these data imply a fail-safe mechanism regulated by autophagy in the action of curcumin, suggesting a therapeutic potential for curcumin, which seems to offer a novel and effective strategy for the treatment of malignant cells ${ }^{47}$.
Curcumin strikingly modulates proteins of iron metabolism in cells and in tissues, suggesting that it has the properties of an iron chelator ${ }^{50-53}$. Because of its polyphenol structure, curcumin forms complexes with a number of different metal ions ${ }^{54}$ and especially with iron $^{51}$. The $\alpha, \beta$ unsaturated $\beta$-diketone moiety of curcumin can form chelates with transition metals. Metal chelates of curcumin are mostly non-fluorescent, although absorption spectra show significant changes that can be tracked to assess the efficiency of chelation. Metal chelates of curcumin of types 1:1 and 1:2 have been reported for the ions $\mathrm{Cu}^{2+}, \mathrm{Fe}^{2+}, \mathrm{Mn}^{2+}, \mathrm{Pb}^{3+}$, and oth$\mathrm{ers}^{55}$. All these metals can play a role in amyloid aggregation, and curcumin is being investigated as a chelating agent for use in the treatment of Alzheimer pathogenesis $^{54}$. Since curcumin is lipophilic and readily crosses membranes, it may also chelate more metal ions intracellularly. ${ }^{56}$ Evidence shows that curcumin is more efficient when low amounts of iron are present intracellularly $y^{53}$. However, how curcumin binds to these metals has not been investigated in detail and nor have the consequences of this interaction in terms of autophagy and cell death mechanisms.

Here we demonstrate that the intracellular chelating activity of curcumin does not change the amount of iron loaded, but that its chelating activity is crucial in inhibiting iron overload cytotoxicity and further effects on liver cell lines. These findings position curcumin as a powerful alternative candidate for the control of liver damage linked to intracellular iron overload.

Moreover, we tested the capability of curcumin as a powerful iron chelator to prevent tumor promotion in T51B and RL-34 cells. Together with the fact that curcumin binds to iron and prevents iron toxicity ${ }^{57-59}$, we have found that curcumin chelation acts like deferoxamine ${ }^{29}$ by inhibiting tumor promotion.

In this context, curcumin may be effective in preventing chemically induced liver damage, by decreasing liver toxicity in rats in the case of galactosamine or carbon tetrachloride poisoning ${ }^{60}$, and also abolishes the carcinogenic effects of aflatoxin and/or nitrosodiethylamine ${ }^{61,62}$.

\section{Results}

\section{Curcumin binds iron}

Spectroscopic shift techniques have shown that iron binds to curcumin in solution ${ }^{54,63}$. Figure 1 illustrates the capability of curcumin to chelate divalent cations, i.e., iron $\left(\mathrm{Fe}^{2+}\right)$. We used an alternative metal affinity chromatography method with handmade Fe-NTA columns. Figure 2a shows the loading efficiency of curcumin from solution to the Fe-NTA-agarose column. Curcumin binding was rapid and efficient, reaching $90-95 \%$ after incubation for $10 \mathrm{~min}$ on the iron-containing resin. It is 


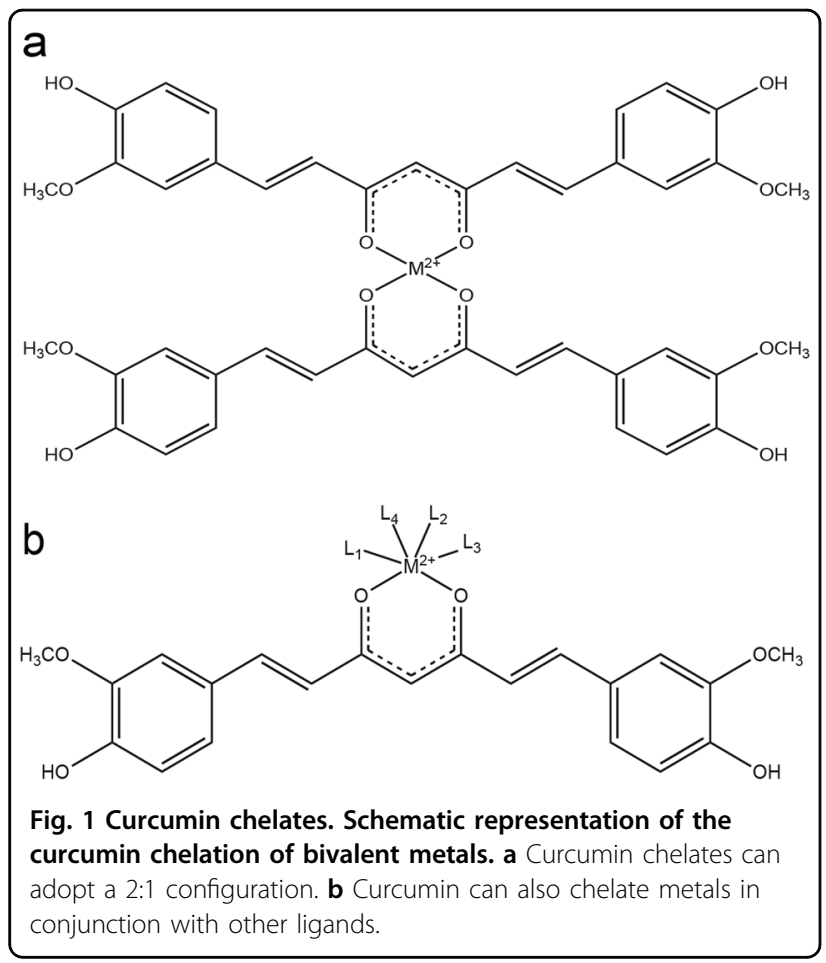

well known that the diketone groups of curcumin likely interact with the Fe-NTA-resin in a similar fashion to the phosphate oxygens of phosphopeptides, for which this iron affinity chromatography resin was developed ${ }^{64}$. The data extracted from Fig. 2 gave an affinity estimation around $\mu \mathrm{M}$, in agreement with the high-affinity iron binding site of curcumin reported by Baum et al. ${ }^{54}$. Comparable curcumin binding was not observed when Fe was replaced by $\mathrm{Ni}$ as the metal ion ${ }^{64}$. A significant fraction of curcumin (based on the absorbance at $435 \mathrm{~nm}$ ) was recovered from Fe-NTA-agarose upon addition of competitive iron chelators like deferoxamine (DFO) or EDTA (and EGTA to a lesser extent) (Fig. 2b). Vitamin $E$ was a much less efficient iron chelator (Fig. 2b). These data reinforce previous reports of iron binding to curcumin and suggest that iron chelation may eventually enable curcumin to reduce both the uptake and toxicity of iron within cells.

The curcumin absorbance spectrum is modified by the presence of Fe-NTA: the absorbance of curcumin was shifted from $435 \mathrm{~nm}$ to $400 \mathrm{~nm}$ for the complex when bound to iron (Fig. 2c). The natural fluorescence of free curcumin, which peaks at $535 \mathrm{~nm}$, was completely quenched when incubated with Fe-NTA, either in emission spectra or microspectrofluorimetry on cells (Fig. 2d, e). Acellular experiments also demonstrated that Fe-NTA added to curcumin induced instantaneous, dose-dependent quenching of curcumin fluorescence (Fig. 2f).

\section{Curcumin efficiently chelates $\mathrm{Fe}^{2+}$ but does not block iron uptake in Huh-7 cells}

The assay of intracellular iron showed that iron chelation by curcumin does not alter cellular iron uptake, whereas curcumin only slightly affected the total amount of intracellular iron (Fig. 3a, b) (the cells were loaded with iron before addition of curcumin to the medium). The detected cellular iron was in the range of $28 \pm 10 \mu \mathrm{g} / \mathrm{g}$ of cells for 48-h incubation with $100 \mu \mathrm{M}$ Fe-NTA, whereas control cells contained 7.2 $\pm 1.9 \mu \mathrm{g}$ iron/g of cells (Fig. 3b). Pre-incubation with DFO and $\mathrm{CoCl}_{2}$ almost totally abolished the iron content of the cells treated with $100 \mu \mathrm{M} \mathrm{Fe}-$ NTA (Fig. 3b), meaning that DFO and $\mathrm{CoCl}_{2}$ act mostly on iron transport activity whereas curcumin acts intracellularly with an almost strict chelating activity (immobilization of the free intracellularly available $\mathrm{Fe}^{2+}$ ).

Additional experiments with calcein, whose fluorescence quenching is strictly correlated with intracellular accumulation of iron, demonstrated efficient quenching by Fe-NTA treatment and FAC. Also, whatever the treatment method used, curcumin complexation with iron completely restored calcein fluorescence (Fig. 4a).

\section{Toxicity features associated with Fe-NTA loading}

Increased loading of Fe-NTA (from 50 to $500 \mu \mathrm{M}$ ) is linearly related to the intracellular iron content (Fig. 3a and Table 1) and is associated with a significant reduction of glutathione activity (Fig. 4b) and glutathione peroxidase activity (GPX4) (Fig. 4c). But there are significant changes only at high doses $(\geq 100 \mu \mathrm{M})$. These events are associated with lipid peroxidation (Fig. 4d) and protein carbonylation (Fig. 4e). These characteristics are widely accepted as the main markers of ferroptosis ${ }^{11,12,65}$ that we discussed in the introduction. However, at the concentration of $100 \mu \mathrm{M}$ Fe-NTA for $48 \mathrm{~h}$ that we currently use in our work, all four of these parameters are discrete and ferroptosis is already engaged in terms of metabolism, but there is not much detectable typical cell death.

\section{Fe-NTA loading of Huh-7 cells leads to ferroptosis}

The effects of iron loading were assayed by multiparametric flow cytometric measurements, which indicate impaired cellular viability and also mitochondrial membrane potential drop $(\Delta \Psi \mathrm{m})$ and annexin- $\mathrm{V}$ positivity (Fig. 6a) and the generation of reactive oxygen species (Fig. 5b), whatever the $\mathrm{H}_{2} \mathrm{O}_{2}$ or superoxide anions generated at the mitochondrial membrane. Classic flow cytometry tests used to determine the induction and nature of cell death by $\mathrm{Fe}^{2+}$ overload show that this cell death is characteristic of apoptosis at very low concentrations [up to $100 \mu \mathrm{M}$ Fe-NTA] and of typical ferroptosis at higher concentrations $(>100 \mu \mathrm{M}$ Fe-NTA, where free or loosely bound iron becomes more cytotoxic). If tested with annexin-V/PI staining, the final death 


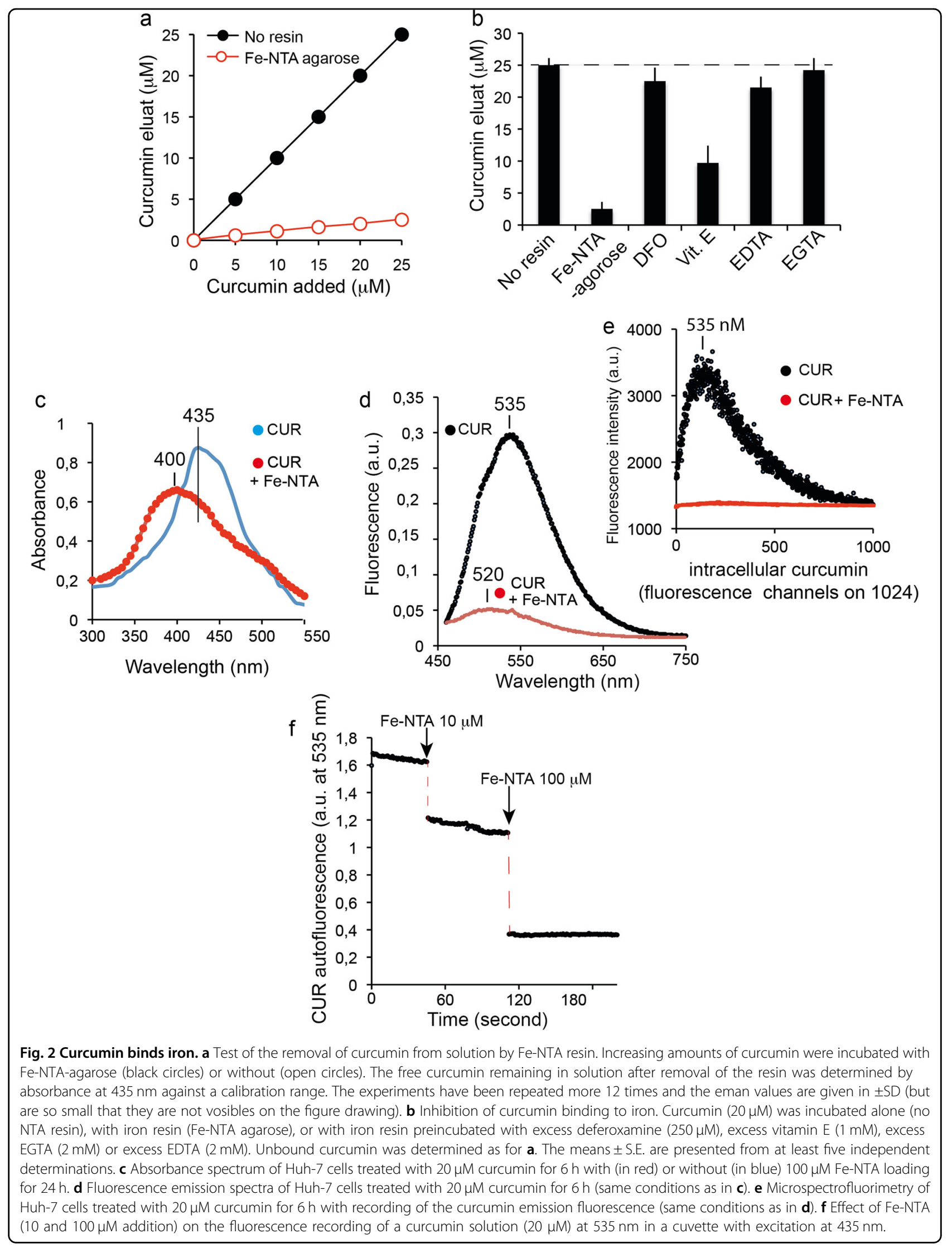




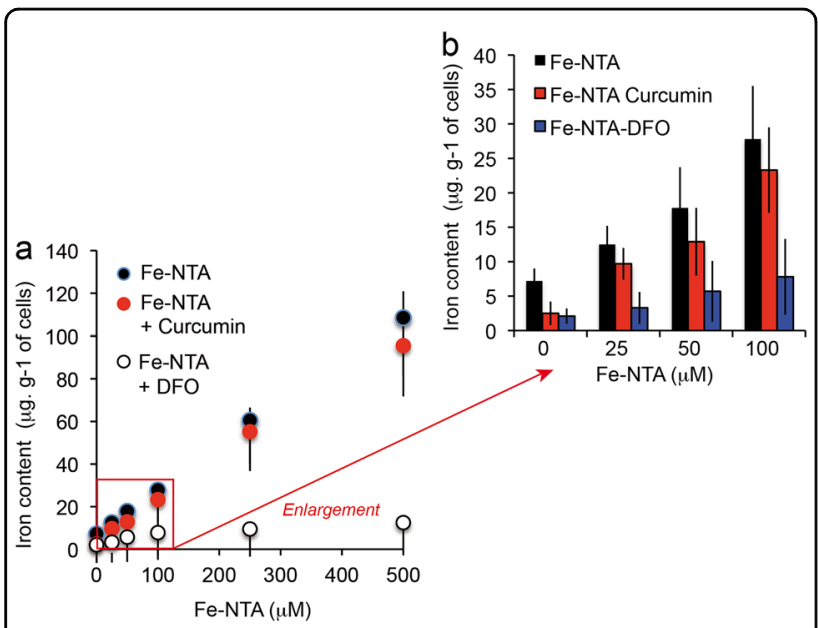

Fig. 3 Cellular iron content after loading with Fe-NTA. a Fe-NTA cell loading $(0-500 \mu \mathrm{M})$ and measurements of the intracellular iron content in presence of deferoxamine or curcumin $(20 \mu \mathrm{M})$. b Enlargement of the Fe-NTA cell loading in the lower range between 0 and $100 \mu \mathrm{M}$ in the presence or absence of deferoxamine (excess, $250 \mu \mathrm{M})$ or curcumin $(20 \mu \mathrm{M})$. For $a$ and $b$, the means \pm S.E. are presented from at least 10 independent determinations.

process resembles that of necrotic cells (they are Annexin- $\mathrm{V}^{+}$and $\mathrm{PI}^{+++}$). Iron-induced cell death is associated with a continuous loss of cell viability (plasma membrane permeability altered with first YO-PRO- ${ }^{+}$ staining at $\mathrm{PI}^{-}$and when $\left[\mathrm{Fe}^{2+}\right]$ increases, the cells become YO-PRO- $1^{+} / \mathrm{PI}^{+}$, as do necrotic cells. But some characteristics of Fe-NTA cell loading are specific: superoxide anion generation, but also quite rapid loss of glutathione activity (Fig. 4d) and glutathione peroxidase depletion (Fig. 4e) associated with lipid peroxidation and protein carbonylation, as described above (Fig. 4f, g). All these data summarized in Table 1 characterize classic ferroptosis at high Fe-NTA concentration, i.e. 250 or $500 \mu \mathrm{M}$ for 48-h incubation. But, in the conditions we currently use with $100 \mu \mathrm{M}$ Fe-NTA and 24-h incubation, we recorded a low level of cell death.

\section{Cell death induction by curcumin}

Huh-7 cells treated with $25 \mu \mathrm{M}$ curcumin for $48 \mathrm{~h}$ and double-stained with YO-PRO-1 versus PI contained different populations, including viable cells $\left(\mathrm{Y}^{-} / \mathrm{PI}^{-}\right)$, apoptotic cells $\left(\mathrm{Y}^{+} / \mathrm{PI}^{-}\right.$or $\mathrm{Y}^{+} / \mathrm{PI}^{\text {intermediate }}$, i.e. slightly positive) and cells undergoing secondary necrosis $\left(\mathrm{Y}^{+} / \mathrm{PI}^{+++}\right)$. Apoptosis peaked at $25 \mu \mathrm{M}$ for $24-\mathrm{h}$ incubation, since a higher curcumin concentration $(50 \mu \mathrm{M})$ favored necrosis (Fig. 5a). It is interesting to note that there is a huge difference between 10 and $25 \mu \mathrm{M}$ curcumin treatment and also that cumulated cell death (apoptosis + necrosis) reached $60-70 \%$ at $25 \mu \mathrm{M}$ curcumin with $24-\mathrm{h}$ incubation. Clearly, that is not the case with $10 \mu \mathrm{M}$ curcumin, where overall cell death reached only $7 \%$ at $48 \mathrm{~h}$.
As curcumin binds to the endoplasmic reticulum ${ }^{44}$ (Rainey N. et al., publication submitted), it is not surprising that the apoptotic processes are linked to calcium release from the endoplasmic reticulum (Fig. 5c) during the first $4 \mathrm{~h}$ of curcumin internalization. This calcium release directly influences mitochondrial behavior, so the mitochondrial membrane potential drop $(\Delta \Psi \mathrm{m})$ (Fig. 5c) together with increased production of superoxide anions (Fig. 5c) is associated with opening of the mitochondrial permeability transition pore. Following this decrease in $\Delta \Psi \mathrm{m}$, there is marked activation of caspase-8 and caspase $3 / 7$, as well as a switch of $\mathrm{NAD}(\mathrm{P}) \mathrm{H}$ and $\mathrm{NADH}$ (fluorescent form) to the reduced forms, $\mathrm{NAD}^{+}$and $\mathrm{NADP}^{+}$ (which are not fluorescent), thus resulting in a drop in $\mathrm{NAD}(\mathrm{P}) \mathrm{H}$ that parallels the $\Delta \Psi \mathrm{m}$ decrease in fluorescence (Fig. 6c). Clearly, if a comparison is made between the apoptosis/necrosis curves and the underlying physiological events, there is a correlation between disruption of mitochondrial homeostasis (i.e. $\Delta \Psi \mathrm{m}$ decrease and $\mathrm{O}_{2}{ }^{--}$production) and the early increase of apoptotic events followed by secondary necrosis (Fig. 6b). Curcumin loading is quite rapid and is associated with an immediate increase in red acridine orange fluorescence indicating early induction of autophagic processes (Fig. 6d). The correlation between red acridine orange fluorescence and LC3-II occurrence has been previously described $^{44}$ and suggests that at certain curcumin concentrations the primary events are linked to autophagic induction.

\section{Iron chelation with curcumin results in a full inhibition of curcumin-induced autophagy and apoptosis}

Figure 6 shows that cells treated with curcumin alone undergo autophagy (Fig. 6d), apoptosis (* in Fig. 6a, b), and necrotic death secondary to apoptosis (Fig. 6a), characterized by a progressive loss of viability, a drop in $\Delta \Psi \mathrm{m}$ associated with increased superoxide anion production and low activation of caspase-8, caspase-3 and caspase-9 (Fig. 6c). Note that caspase- 8 is only secondarily activated as a consequence of lysosomal membrane permeabilization, which is caused by curcumin binding [44] and occurs upstream of ER membrane damage. Then, caspase- 8 activated by cathepsin release from the lysosomes induces additional destabilization of the mitochondrial compartment through tBid generation and cytochrome $c$ release, which results in activation of caspase-3/-7 and -9 .

$\mathrm{Fe}^{2+}$ chelation completely abolishes curcumin's capacity to induce cell death. The expression of phosphatidyl serine at the cell membrane (late apoptotic and necrotic event) is abolished, as is the $\Delta \Psi \mathrm{m}$ drop usually detected as an early event (Fig. 6a). The production of ROS, superoxide anions (Fig. 6b, upper and lower right panels) and hydroperoxides associated with mitochondrial 

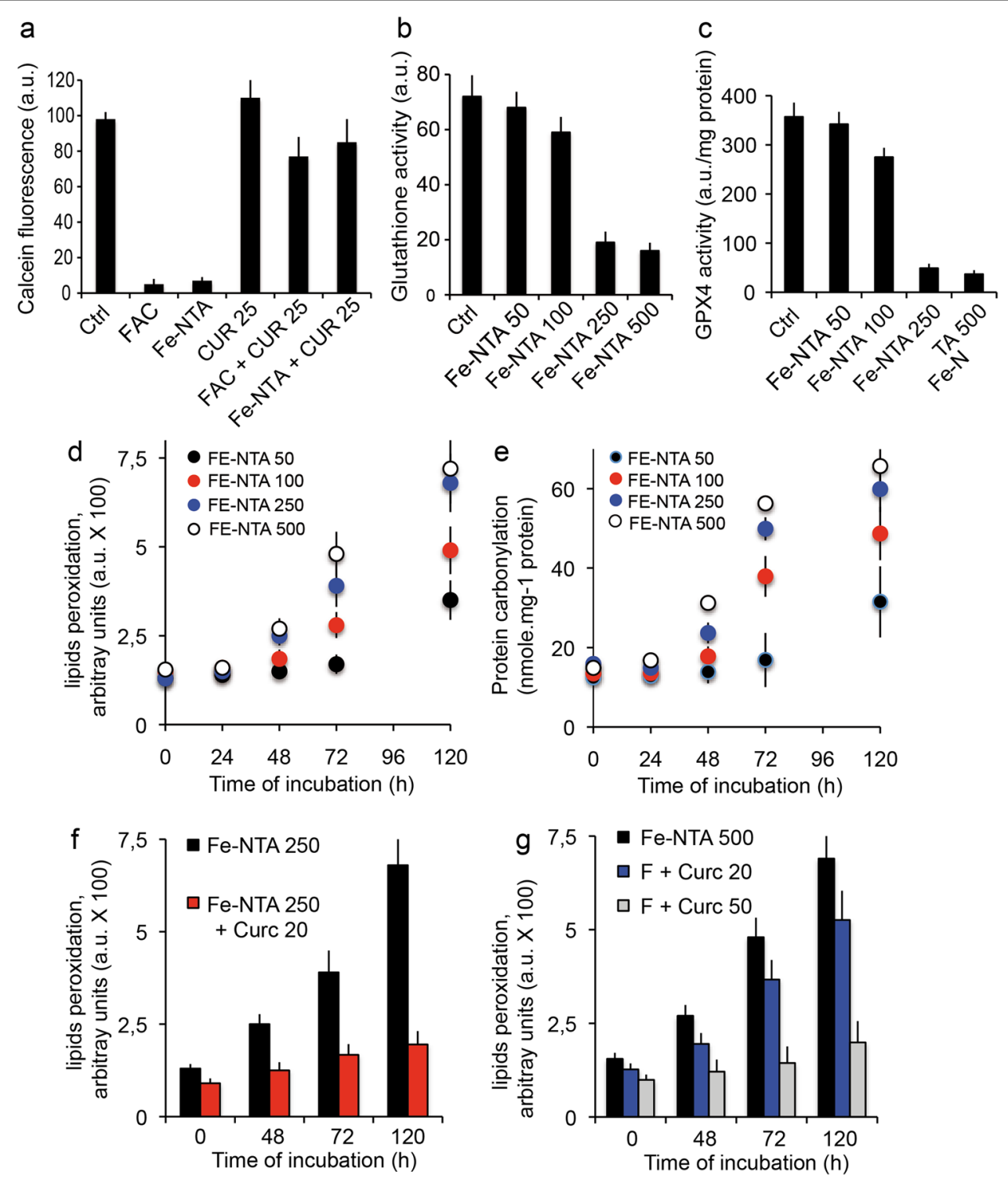

Fig. 4 Cellular metabolic events. a Cells were charged with calcein-AM and either FAC (200 $\mu$ M) or Fe-NTA (100 $\mu$ M) and compared with cells loaded with curcumin only $(20 \mu \mathrm{M})$. Cells were simultaneously treated with FAC and curcumin or Fe-NTA and curcumin. After $1 \mathrm{~h}$, the cells were rinsed with phosphate buffer saline (PBS) on ice and calcein fluorescence was measured. ( \pm SD for six repeated experiments). $\mathbf{b}$ Effect of iron loading by cell loading with 0-500 $\mu \mathrm{M}$ Fe-NTA and its effect on glutathione activity. $( \pm$ SD for eight repeated experiments). $\mathbf{c}$ Effect of iron loading (as in d) on lipid peroxidation as a function of time (0-120 h). d Effect of iron loading (as in d) on protein carbonylation as a function of time (0-120 h).

e Measurement of high doses of iron loaded with $250 \mu \mathrm{M}$ Fe-NTA in the presence of $20 \mu \mathrm{M}$ curcumin. $\mathbf{f}$ Measurement of high doses of iron loaded with $500 \mu \mathrm{M}$ Fe-NTA and $20 \mu \mathrm{M}$ or $50 \mu \mathrm{M}$ curcumin. All experiments presented in $\mathrm{c}$ to $f$ are the mean \pm SD for 10 repeated experiments.

homeostasis disruption is controlled (Fig. 6b). Also, a large panel of metabolic characteristics that are regulated by curcumin-induced cell death are completely inhibited. The mitochondrial membrane potential is high and NAD (P)H fluorescence usually too. Also, caspase- $3 / 7,-8$ and -9 are no longer activated, as they were with curcumin treatment alone (Fig. 6c). Moreover, the red acridine orange fluorescence linked to the increasing amount and bigger size of acidic vesicles linked to autophagy enhancement almost falls to control levels (Fig. 6d), whatever the curcumin concentration up to $50 \mu \mathrm{M}$. Curcumin-induced autophagy diminishes with increasing curcumin concentration because apoptosis and necrosis occur as curcumin becomes cytotoxic for the cells (Fig. 6d). Below $10 \mu \mathrm{M}$, curcumin usually does not promote cell death, but autophagy is engaged. Above $10 \mu \mathrm{M}$, the number of acridine orange-positive cells decreases as apoptosis and secondary necrosis occurs. 
Table 1 Regulation of the main metabolic events linked to ferroptosis induction.

\begin{tabular}{|c|c|c|c|c|}
\hline Treatment & Control cells & $\begin{array}{l}+ \text { Fe-NTA } \\
500 \mu \mathrm{M}\end{array}$ & $\begin{array}{l}+ \text { Fe-NTA } 500 \mu \mathrm{M} \\
+ \text { Curcumin } 20 \mu \mathrm{M}\end{array}$ & $\begin{array}{l}+ \text { Fe-NTA } 500 \mu \mathrm{M} \\
+ \text { Curcumin } 50 \mu \mathrm{M}\end{array}$ \\
\hline Iron amount $\mu \mathrm{g} / \mathrm{g}$ cells & $7.2 \pm 1,9$ & $114 \pm 10.6$ & $109 \pm 9.5$ & $109 \pm 19.5$ \\
\hline Gluthatione activity (a.u.) & $74 \pm 8,2$ & $17 \pm 5.3$ & $39 \pm 8.4$ & $69 \pm 7.9$ \\
\hline GPX4 activity a.u./mg protein & $370 \pm 25.2$ & $28 \pm 7.2$ & $130 \pm 31.9$ & $350 \pm 29.4$ \\
\hline Lipid peroxidation a.u. X 100 & $1.6 \pm 0.3$ & $7,3 \pm 1.4$ & $3,9 \pm 0,9$ & $1,7 \pm 0.2$ \\
\hline $\begin{array}{l}\text { Protein carbonylation nmole/mg } \\
\text { protein }\end{array}$ & $17.3 \pm 0.5$ & $67,5 \pm 8,7$ & $29,9 \pm 7.2$ & $17,1 \pm 0.4$ \\
\hline Necroptosis (\% of cells PI +++ ) & $9 \pm 3.2$ Necrosis in culture & $90 \pm 6.4$ & $39 \pm 7.3$ & $14 \pm 5.9$ \\
\hline
\end{tabular}

\section{Iron chelating activity of curcumin alleviates its tumor- promoting effect}

To assess whether curcumin, as a potent iron chelator, can also reduce or prevent the tumor-promoting effect of iron overload, we used T51B (rat liver epithelial cell) and RL-34 (rat liver epithelial diploid cell line). We chose to use the Xcelligence impedancemetry to set up the correct time for the seeding of the cells on soft agar, and decided to take the cells after $36 \mathrm{~h}$ when their proliferation peaks (Fig. 7b, indicated by an arrow). This was done for both T51B and RL-34 cell lines. Previous studies show that iron acts as a tumor promoter in T51B cells, with FAC induction associated with a low dose of MNNG generally acting by successive cycles of hepatotoxicity followed by regrowth and regeneration ${ }^{66}$. Acute iron overload was achieved with $250 \mu \mathrm{M}$ Fe-NTA or with FAC + 8HQ for 7 days in the absence or presence of increasing amounts of curcumin.

The two cell lines exhibited similar behavior and $50 \mu \mathrm{M}$ curcumin was enough to efficiently counteract iron overload toxicity (Fig. 7b, b) in the case of RL-34. The results (not shown) were very similar with the T51B cells.

Whatever the iron overload protocol, the induction of colonies took over 12 weeks of repeated cycles of cell culture on soft agar, and the number of colonies was quite significant at 20 weeks of culture (over 120 colonies of 25,000 cells) (Fig. 7d). By chelating iron, curcumin controls colony development and after 20 weeks of culture of both cell lines the number of colonies did not exceed five (Fig. 7d).

\section{Discussion}

\section{Curcumin-iron interactions}

Cyclic voltammetry experiments show that curcumin binds metal ions and especially $\mathrm{Fe}^{2+, 67}$. The iron chelation activity of curcumin is related to its chemical structure via the $\beta$-diketone group, a known bidentate chelator of $\mathrm{Fe}^{2+}$, similar to the group found in simple analogous complexes of $\mathrm{Fe}(\mathrm{III})$ and acetylacetonate. Based on the formation constant of $\mathrm{Fe}(\mathrm{III})$-curcumin of $10^{22} \mathrm{M}^{-1,67}$, it has been calculated that the $\mathrm{pFe}^{2+}$ ("pM") of curcumin is 16.6 (at $\mathrm{pH} 7.4$ for $10 \mu \mathrm{M}$ curcumin and $\left.1 \mu \mathrm{M} \mathrm{Fe}{ }^{2+, 68}\right)$. This curcumin $\mathrm{pM}$ is not as high as the $\mathrm{pM}$ of other iron chelators already used in iron-overload treatment, such as deferiprone $(\mathrm{pM}=20)$ and deferoxamine $(\mathrm{pM}=26)^{68}$. Curcumin $\mathrm{pM}$ compares favorably with the $\mathrm{pM}$ of the iron chelator nitrilotriacetic acid (NTA), which we use on the nickel column for extraction of curcumin and many other iron chelators (Fig. 1) and fits well with other iron chelating activity detected in vitro ${ }^{68}$. The methods used for loading iron into cells yield endogenous iron contents ranging from $7.2 \pm 1.9 \mu \mathrm{g}$ iron/g of cells to $28 \pm 10 \mu \mathrm{g} / \mathrm{g}$ of cells, for 48-h incubation with $100 \mu \mathrm{M}$ Fe-NTA (Fig. 3a). These results are not altered by the deleterious effect of iron, as its toxicity becomes significant only above $100 \mu \mathrm{M}$ and for longer time periods. Iron toxicity is associated with lipid peroxidation and protein carbonylation (Fig. 4d, e, g) and a decrease in intracellular protection against ROS-like glutathione activity (Fig. 4b, c). Iron accumulation at higher Fe-NTA concentrations for $48 \mathrm{~h}$ leads to intracellular accumulation of $60.5 \pm 13.2$ and $108.5 \pm 19.6 \mu \mathrm{g} / \mathrm{g}$ for Fe-NTA 250 and $500 \mu \mathrm{M}$, respectively (Table 1 ). These conditions of loading go beyond the capacity of the endogenous antioxidant defense system, with clear depletion of glutathione activity, which is overwhelmed by massive generation of ROS from cellular $\mathrm{Fe}^{2+}$ engaged in Fenton reactions/ Haber-Weiss reactions ${ }^{2,3}$.

Although curcumin clearly binds iron, there is no significant reduction in iron uptake by cells (Fig. 3a), though there may be a discrepancy due to transient interaction between curcumin and the plasma membrane during primary penetration, when it could interact with the iron regulation system. So, our data show that curcumin binding to iron does not influence intracellular iron levels in response to Fe-NTA treatment. We therefore investigated whether curcumin chelation of iron is still hermetic behavior or whether its activity is altered. 

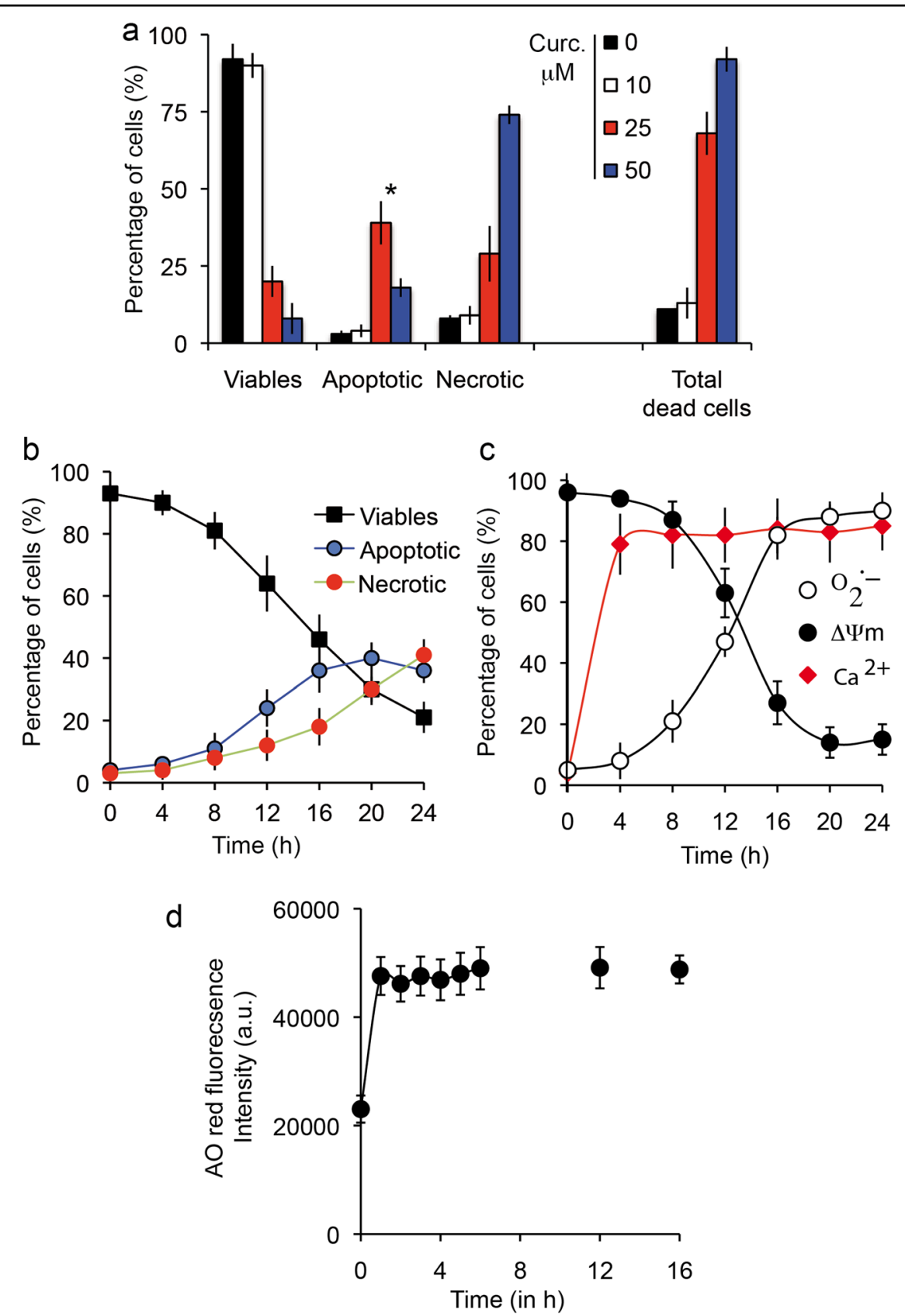

Fig. 5 Prototypic induction of cell death by curcumin. a Flow cytometry analysis of Huh-7 cell death. Percentage of viable, apoptotic and necrotic cells among cells treated with various concentrations of curcumin (0-50 $\mu \mathrm{M}$ for 24-h incubation). YO-PRO-1/PI staining was used to analyze membrane permeability and discriminate three populations: $\mathrm{YO}-\mathrm{PRO}-1^{-} / \mathrm{PI}^{-}$for viable cells, $\mathrm{YO}-\mathrm{PRO}-1^{+} / \mathrm{PI}^{-}$or $\mathrm{YO}-\mathrm{PRO}-1^{+} / \mathrm{PI}$ intermediate for apoptotic cells and $\mathrm{YO}-\mathrm{PRO}-1^{+} / \mathrm{PI}^{+}$for necrotic cells. Asterisk inidicates the maximal number of apoptotic cells was observed at $25 \mu \mathrm{M}$ curcumin for $24 \mathrm{~h}$. Data are expressed as the mean \pm S.D. $(n=7)$. b Same as in panel a but plotted as a function of time from 0 to $24 \mathrm{~h}$ for $25 \mu \mathrm{M}$ curcumin. Data are expressed as the mean \pm S.D. $(n=7)$. c Metabolic measurements linked to dying cells after $24-h$ incubation with $25 \mu \mathrm{M}$ curcumin. Mitochondrial membrane potential with $\mathrm{DiOC}_{6}(3)$ fluorescence $\left(\Delta \psi_{\mathrm{m}}\right.$, black circles), superoxide anion generation tested with MitoSOX-green fluorescence $\left(\mathrm{O}_{2}{ }^{-}\right.$, empty circles) and calcium increase measured with Fluo 4-AM (intracellular calcium, red diamonds). Data are expressed as the mean \pm S.D. ( $n=10$ ).

\section{Curcumin cellular effects}

We investigated the Huh7 profile response to curcumin as previously ${ }^{44}$ and confirmed that curcumin affects the ER via calcium release taken up by mitochondria via the mitochondrial calcium uniporter, resulting in a drop in $\Delta \Psi \mathrm{m}$ and superoxide anion production, leading ultimately to opening of the mitochondrial permeability transition pore (Fig. 5c). These results suggest the further 

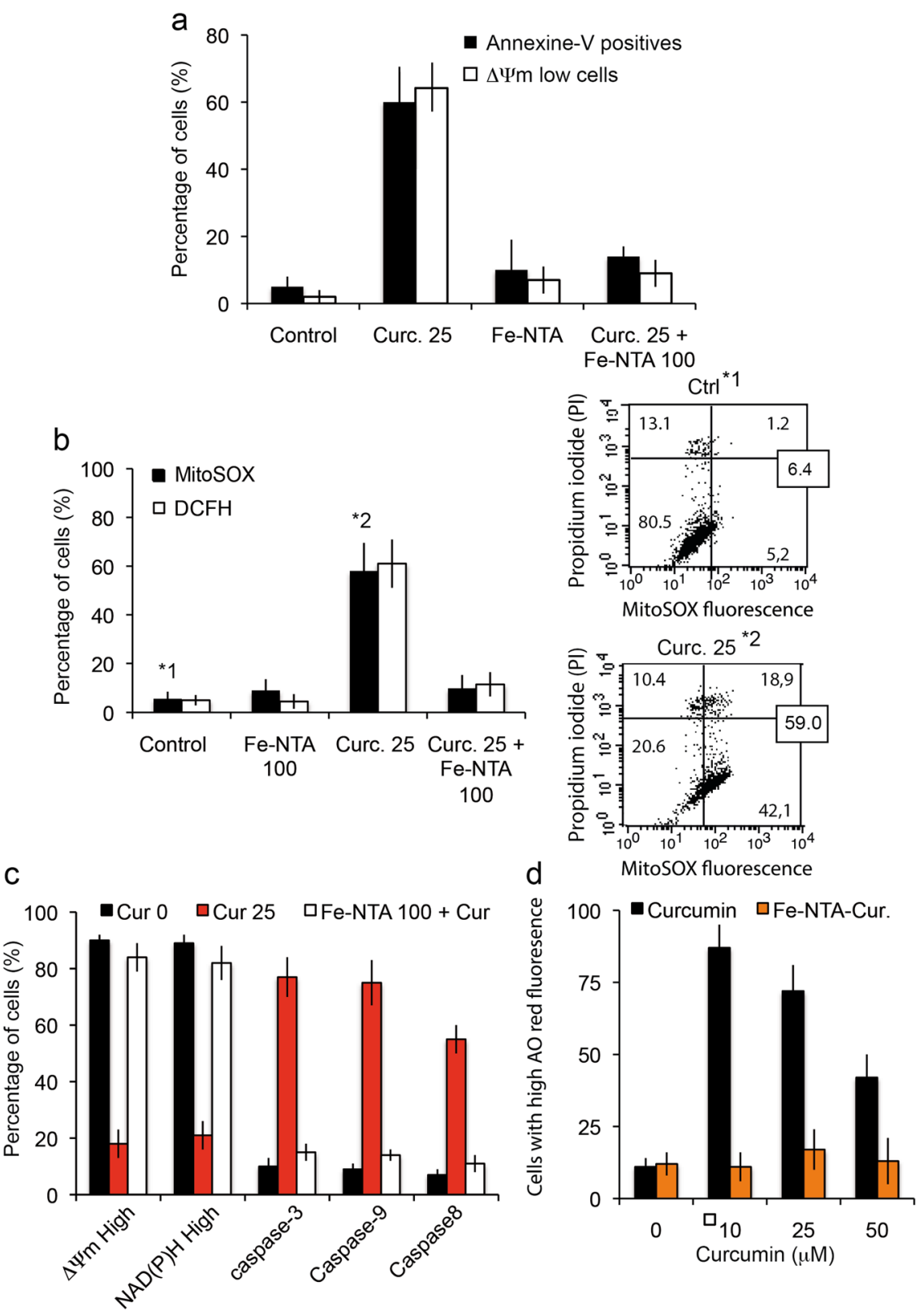

Fig. 6 Cell death induced by curcumin and Fe-NTA-curcumin complex. a Flow cytometry analysis of early and late events during cell death (respectively, drop in mitochondrial membrane potential $(\Delta \psi \mathrm{m})$ and PS exposure) when cells are treated for $24 \mathrm{~h}$ with curcumin $(20 \mu \mathrm{M})$ or Fe-NTA $(100 \mu \mathrm{M})$ alone or with both, which behave intracellularly as chelators. The results are issued from 7 independent experiments. b Flow cytometry analysis of the events following the $\triangle \psi_{m}$ drop (in a): generation of superoxide anions (MitoSOX staining) and hydroperoxide production (DCFH-DA staining. Each histogram is from seven independent experiments and \pm SD is given. Control and $20 \mu \mathrm{M}$ curcumin ( $24 \mathrm{~h}$ ) conditions are illustrated respectively in $1^{*}$ and $2^{*}$ by biparametric plots together with the viability measurement (PI staining). The percentage of cells in each panel is given as a percentage (\%) of the whole population. c Broad metabolic analysis showing that treatment with both products restores control conditions, with respectively a large population of high $\triangle \psi_{\mathrm{m}}$ and $\mathrm{NAD}(\mathrm{P}) \mathrm{H}$ together with low activation of the so-called "initiation caspase" (caspase-8) and "executioner caspases" (caspase-3,-7 and caspase-9). Cells were treated with $20 \mu \mathrm{M}$ curcumin or $100 \mu \mathrm{M}$ Fe-NTA or both. d Cells were treated for $24 \mathrm{~h}$ with curcumin or Fe-NTA, or both. Then we analyzed red acridine orange fluorescence. As curcumin alone induces low pH vesicle staining which can be related to autophagy induction (more lysosomes and appearance of autophagic vesicles,) the Fe-NTA-curcumin complex abolishes that increase and returns to baseline level. 

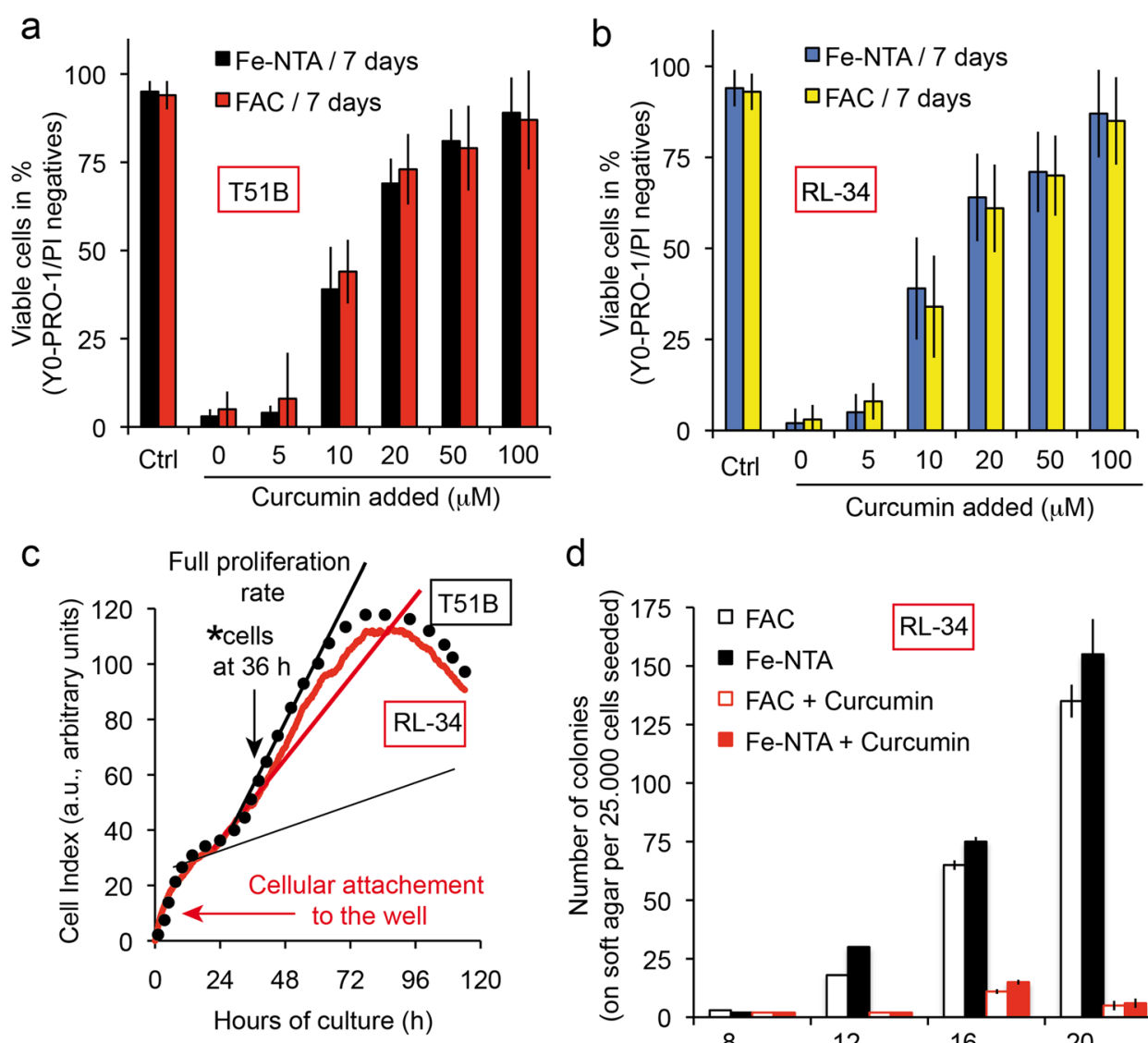

d

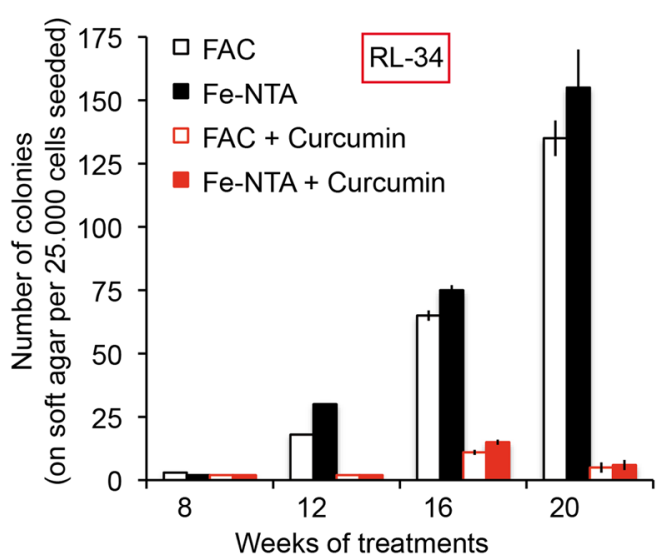

Fig. 7 Curcumin chelate with free iron alleviates the tumor-promoting activity of Fe-NTA or FAC. a T51B cells are protected against free iron toxicity by curcumin in a concentration-dependent manner. Epithelial T51B cells were treated for 7 days with either $100 \mu \mathrm{M}$ Fe-NTA or $100 \mu \mathrm{M}$ FAC ( $+10 \mu \mathrm{M}$ hydroxyquinoline) and various curcumin concentrations and then viability-tested by cytometry taking into account the dead cells (apoptotic, A and necrotic, $N$ cells) to find the cellular viability $[100-(A+N)=$ viable cells in percentage]. b Same as in a, but with RL-34 cells. c The cells used in the c experiment were taken at $36 \mathrm{~h}$ in their full proliferation phase after plating. The situation was tested by impedancemetry using the ACEA Xcelligence system. Arrows (black) indicate the situation of the cells at $36 \mathrm{~h}$ and the arrow (in red) early in the curve indicates the initial cell binding to the wells, which in our case took almost $24 \mathrm{~h}$ before full proliferation. The curve is drawn taking into account the mean value for 12 different wells. $\mathbf{d}$ T51B cells plated at $2.10^{5}$ cells in $60 \mathrm{~mm}$ dishes were treated with MNNG $(0.5 \mathrm{mg} / \mathrm{mL}$ for $24 \mathrm{~h})$ after plating and cultured with either $20 \mu \mathrm{M}$ curcumin or Fe-NTA $200 \mu \mathrm{M}$ (or FAC $250 \mu \mathrm{M}$ with 8-hydroxyquinoline), or both. The culture medium was renewed every 2-3 days with fresh media. T51B cells were trypsinized before they became confluent (day 4-6). The culture continued for up to 20 weeks and colony formation was tested every two weeks, special care being taken when formation became greater at 16, 18, and 20 weeks of culture). The number of soft agar experiments conducted was $n=7$ and \pm SD are indicated. MNNG was added at the start to participate in the initiation of tumorigenesis.

involvement of cathepsins and caspase-8 activation leading to cytochrome c release and apoptosis, as previously described $^{44}$. This does not exclude early involvement of lysosomes, as it is clear that curcumin in the $\mu \mathrm{M}$ range induces autophagic processes (Fig. $5 \mathrm{~d}$ ) ${ }^{44}$. This may explain published observations on the acceleration of neoplastic transformation when $10-20 \mu \mathrm{M}$ curcumin is added to iron $^{29,69}$. It is possible that $10-20 \mu \mathrm{M}$ curcumin is more than enough to chelate all iron and that the remaining ironfree curcumin induces autophagy, enhancing neoplastic transformation ${ }^{44,47}$. Indeed, in neoplastic cells, autophagy is a mechanism for coping with intracellular and environmental stress, thus favoring tumor progression ${ }^{70}$.

\section{Curcumin-iron chelates abolish both curcumin effects and iron cytotoxicity}

When chelated with iron, curcumin loses its capacity to induce toxicity and cell death (Fig. 6), which is in line with previous reports showing that iron attenuates curcumin's cytotoxic effects in squamous cell carcinoma ${ }^{71}$. Chelation abolishes late stage signals like outer exposure of phosphatidyl serine (Fig. 6a), but also early production of both hydrogen peroxide and superoxide anions from the mitochondrial compartment (Fig. 6b). These results fit with other inhibition linked to cell death, like the drop in mitochondrial potential, reduction of $\mathrm{NAD}(\mathrm{P}) \mathrm{H}$, and activation of caspases $3 / 9 / 8$ (Fig. 6c). These results 
contrast with the ongoing hypothesis that combination of ions and ligands would produce a synergistic effect on cells ${ }^{72-74}$. A possible explanation may come from the fact that the keto-enol function and related hydrogen that is locked with metals are unable to produce oxyradicals unless there is complete dissociation. According to these data, the keto-enol function is also likely to drive the curcumin-induced autophagic process (Fig. 6d). Another hypothesis to consider would be the modification of the size and steric hindrance of the curcumin chelate compared to free curcumin, which would open up a new set of possible mechanisms yet to be studied.

We used the soft agar tumorigenesis model to investigate for longer periods how RL-34 cells respond to ironinduced stress (with an MNNG starter) and curcumin treatment. As FAC or Fe-NTA treatment $(250 \mu \mathrm{M})$ produced large numbers of colonies, $20 \mu \mathrm{M}$ curcumin is enough to abolish that growth (Fig. 7d). Messner and colleagues recently found this same response for $20 \mu \mathrm{M}$ curcumin, but observed tumor promotion for $10 \mu \mathrm{M}$ curcumin in the same settings ${ }^{69}$. We hypothesize that $10 \mu \mathrm{M}$ curcumin is already in excess compared to free iron, especially if curcumin can cycle the iron to transferrin and maintain it in the redox inactive state ${ }^{52}$. That excess is not enough to induce apoptosis and control tumorigenesis like $20 \mu \mathrm{M}$ does (Fig. $7 \mathrm{~d}$ ), but is enough to stimulate autophagic processes and therefore boost tumorigenesis.

In a clinical cancer setting, we would need to address a specific curcumin payload, either partially chelating iron to reduce this tumor-promoting signal or increasing the payload enough to produce apoptosis and not boost autophagy.

Iron-overload diseases are not subject to this limitation, and while iron chelation is sought, an extra autophagic signal could be valuable for patients at the tissue level, as could the anti-oxidative properties provided by low concentrations of curcumin.

\section{Materials and methods}

\section{Chemicals and reagents}

Calcein-AM, curcumin, deferoxamine, 8-hydroxyquinoline (8-HQ), ferric ammonium citrate (FAC), propidium iodide (PI), $\mathrm{N}$-acetylcysteine (NAC) were from SigmaAldrich Chemical Co. (St. Louis, MO, USA). Calcein-AM, 2,7-dichlorodihydrofluorescein diacetate (DCFH-DA), 3,3'dihexyloxacarbocyanine iodide $\left[\mathrm{DiOC}_{6}(3)\right]$ and $N$-[4-[6[(acetyloxy) methoxy]-2,7-dichloro-3-oxo-3H-xanthen-9yl]-2-[2-[2-[bis[2[(acetyloxy) methoxy]-2-oxyethyl] amino]5-methyl-phenoxy] ethoxy]phenyl- $\quad N$-[2-[(acetyloxy) methoxy]-2-oxyethyl]-(acetyloxy) methyl ester (Fluo-4/ AM) were from Molecular Probes (Invitrogen, Eugene, OR, USA). Agarose was from Lonza (Walkersville, MD, USA.
8-Hydroxyquinoline was given together with FAC to enhance its internalization.

\section{Cells}

Human hepatoma-derived Huh-7 cells were from the RIKEN BioResource Center, Tsukuba, Japan and were grown in the presence of $5 \% \mathrm{CO}_{2}$ with Dulbecco's modified Eagle's medium (DMEM) containing high glucose (25 mM Sigma-Aldrich, St. Louis, MI) with $10 \%$ fetal bovine serum (FBS, Hyclone, Logan, UT) completed with $1 \%$ penicillin-streptomycin, HEPES $\mathrm{NaOH} 1 \mathrm{mM}$, Napyruvate $1 \mathrm{mM}$ and $1 \%$ non-essential amino acids (MEAM, GIBCO). T51B cells (rat epithelial cell lines, non-neoplastic) are a model for the study of tumor promotion in vitro. They can be transformed to grow in soft agar by treatment with small amounts of carcinogens and tumor promoters ${ }^{75}$. RL-34 cells (rat liver epithelial-like cells, non-neoplastic from JCrB Bank, Japan) were maintained in the same medium as T51B cells.

\section{Cell culture, iron overload and neoplastic transformation}

The neoplastic transformation of T51B and RL-34 cells was done as described by Messner et al. ${ }^{69}$ and the colony formed on soft agar counted as a transformation index ${ }^{75}$. We followed exactly the previous transformation protocol with a single 24 -h treatment with $0.5 \mu \mathrm{g} / \mathrm{mL} \mathrm{N}$-methyl- $N$ '-nitrosoguanidine (MNNG) followed by continuous culture for weeks either with ferric ammonium citrate (FAC) plus 8 -HQ or $250 \mu \mathrm{M}$ Fe-NTA with or without $25 \mu \mathrm{M}$ curcumin.

\section{Intracellular iron dosage}

Intracellular iron contents of Huh7 cells given in micrograms of iron per gram of cells were determined after treatment with $100 \mu \mathrm{M}$ Fe-NTA and/or $100 \mu \mathrm{M}$ DFO for $24 \mathrm{~h}$. Cell cultures $\left(150 \mathrm{~cm}^{2}\right.$ at $80 \%$ confluence) were trypsinized and collected with lysate buffer (trichloroacetic acid $0.1 \mathrm{~g} / \mathrm{L}$, hydrochloric acid $0.774 \mathrm{M}$, mercaptoacetic acid $30 \mathrm{mM}$ ) to give $100 \mathrm{mg}$ of cells for $400 \mu \mathrm{L}$ buffer. Lysate was heated to $65^{\circ} \mathrm{C}$ overnight and centrifuged. Supernatants were then analyzed by flame emission spectrometry (Institut Claude Bernard, ICB, Paris) and compared to standards to determine iron content.

\section{Iron affinity resin}

Fe-NTA-agarose was constructed from commercially available nickel NTA agarose (Qiagen, S.A., France). The Ni-NTA agarose was stripped with EDTA and recharged with iron as described ${ }^{64}$. Binding and pull-down experiments were performed in 50\% ethanol and assumed 100\% replacement of $\mathrm{Ni}$ sites with $\mathrm{Fe}^{2+}$ (as guaranteed by the manufacturer). For the binding experiments, the indicated amounts of curcumin were incubated with or without 
Fe-NTA-agarose in 50\% ethanol at room temperature (roughly $25 \mathrm{nmol}$ metal binding sites in $0.5 \mathrm{~mL}$ total volume). After $10 \mathrm{~min}$, the resin was removed by centrifugation, and aliquots of the supernatants were diluted as needed (10-fold) to determine the curcumin remaining in solution (absorbance at $435 \mathrm{~nm}$ ). Affinity estimations were based on the method of Scatchard, assuming free curcumin equal to the amount remaining in solution in the presence of Fe-NTA-agarose, and bound curcumin equal to the amount of curcumin added minus the free curcumin measured at each concentration shown. The experiments were conducted exactly as described by Messner et al. ${ }^{52}$.

\section{Determination of lipid peroxidation and protein carbonylation}

We used a lipid peroxidation assay kit (Abcam) to detect malondialdehyde (MDA) in samples. The free MDA generated during lipid peroxidation refers to the oxidative degradation of lipids reacting with thiobarbituric acid (TBA) to generate an MDA-TBA adduct. The absorbance of MDA-TBA adduct was measured at $532 \mathrm{~nm}$ for a sensitivity as low as $1 \mathrm{nmol} /$ well. For the calculation, we determined the MDA concentration in standards and samples from their absorbance as described in the protocol of the lipid peroxidation assay kit from Abcam (ab118970). Protein carbonylation was assayed in Huh-7 cell lysates using Cayman's Protein Carbonyl Fluorometric Assay Kit.

\section{Microspectrofluorimetry}

The UV-visible confocal laser microspectrofluorometer prototype was built around a Zeiss UMSP80 UV epifluorescence microscope (Carl Zeiss, Inc., Oberkochen, Germany), optically coupled by UV reflecting mirrors to a Jobin-Yvon HR640 spectrograph (ISA, Longjumeau, France $)^{76}$. The 351-nm UV line of an argon laser (model 2025; Spectra-Physics, Mountain View, CA) was used for either drug or fluorochrome excitation. The diameter of the laser beam is first enhanced through a double-lens beam expander in order to cover the entire numerical aperture of the microscope's optics. The laser beam is then deflected by the epi-illumination system (dichroic mirror or semireflecting glass) and focused on the sample through the microscope objective (X63 Zeiss Neofluar water-immersion objective; numerical aperture $=1.2$ ) on a circular spot $0.5 \mu \mathrm{m}$ in diameter. The excitation power is reduced to less than $0.1 \mu \mathrm{W}$ by neutral optical density filters. The objective was immersed in the culture medium, and a circular area $0.8 \mu \mathrm{m}$ in diameter was selected at the sample level, by interposing a field diaphragm on the emission pathway of the microscope, to selectively collect the fluorescence signal from the nucleus or a specific cytoplasmic area. Confocal conditions are met when the image of this analysis field diaphragm through the microscope objective perfectly coincides with the focus of the laser beam on the sample.

Under these conditions, the experimental spatial resolution, measured on calibrated latex beads (2, 0.6, and $0.16 \mu \mathrm{m}$ in diameter) labeled with the fluorescent probe fluorescein, is $0.5 \mu \mathrm{m}$ for the directions $\mathrm{X}, \mathrm{Y}$, and $\mathrm{Z}$. Finally, the fluorescence spectra were recorded after spectrograph dispersion, in the $380-630 \mathrm{~nm}$ region on a 1024 diode-intensified optical multichannel analyzer (Princeton Instruments, Inc., Princeton, NJ) with a resolution of $0.25 \mathrm{~nm} /$ diode. Each fluorescence emission spectrum was collected from 1 to $10 \mathrm{~s}$. Data were stored and processed on an 80286 IBM PS/2 microcomputer using the Jobin-Yvon "Enhanced Prism" software. It should be noted that, in order to avoid any possible fluorescence from a plastic or glass support during analysis with near-UV excitation, cells were grown on quartz plates that were then placed on the microscope stage in $50-\mathrm{mm}$ thermostated Petri dishes, filled with $5 \mathrm{~mL}$ of phosphate buffered saline (PBS). A uranyl glass bar was used as a fluorescence standard to control laser power and instrumental response and to enable quantitative comparison between spectra recorded on different days. Sample heating, photobleaching, and photo damage were assessed empirically and found to be negligible under our experimental conditions. In particular, cells always remained viable after repeated fluorescence determinations, as checked by phase-contrast microscopy.

\section{Determination of cellular viability, mitochondrial} membrane potential $(\Delta \Psi \mathrm{m})$, reactive oxygen species and cytosolic $\mathrm{Ca}^{2+}$ levels

A density of $2 \times 10^{6}$ Huh-7 cells on six-well plates were maintained with $25 \mu \mathrm{M}$ of curcumin for a given period of time ranging from 0 to $48 \mathrm{~h}$ depending on the experiments. After treatment, cells were trypsinized, harvested, washed and then resuspended together with their supernatant in PBS. 3,3'-Dihexyloxacarbocyanineiodide $\left[\mathrm{DiOC}_{6}(3)\right]$ was added to a final concentration of $40 \mathrm{nM}$ for $\Delta \Psi \mathrm{m}$ determination, $2^{\prime}, 7^{\prime}$-dichlorodihydrofluorescein diacetate (DCFH-DA) to $5 \mu \mathrm{M}$ for $\mathrm{H}_{2} \mathrm{O}_{2}$, and MitoSOX to $1 \mu \mathrm{M}$ for superoxide anion. Most of the time double staining was done in order to assay simultaneously cellular viability, with propidium iodide (PI: stock solution; $1 \mathrm{mg} \mathrm{mL}^{-1}$ ) for $\operatorname{DiOC}_{6}(3)$, DCFH-DA and Fluo4-AM and with $2 \mu \mathrm{g} / \mathrm{mL}$ TO-PRO-3 iodide (stock solution; $1 \mathrm{mg}$ $\mathrm{mL}^{-1}$ ) for MitoSOX. Supplemental double staining was used for the distinction between viable, apoptotic and necrotic cells with YO-PRO-1 / PI (Molecular Probes) in parallel with annexin-V/PI staining done with annexin-VFITC when needed (Immunotech, Beckman-Coulter). All samples were analyzed by flow cytometry as previously described $^{77,78}$ on a FACS Calibur 4C. 


\section{Use of monochlorobimane for detection of intracellular GSH activity}

The Huh-7 cell content of GSH was determined using $50 \mu \mathrm{M}$ monochlorobimane $(\mathrm{mBCl})$ in 20 -min incubation at room temperature in the $\operatorname{dark}^{78}$. Monochlorobimane (Molecular Probes, Eugene, OR) was dissolved in 100\% ethanol to a stock concentration of $40 \mathrm{mM}$ and stored at $-20^{\circ} \mathrm{C}$. Special precautions were used to minimize the exposure of $\mathrm{mBCl}$ to ambient light. To assess $\mathrm{mBCl}$ for detection of intracellular GSH, Huh-7 cells were also incubated with $\mathrm{N}$-ethylmaleimide (NEM; Sigma) as a control, a GSH depleting agent, which has been used previously to establish the specificity of $\mathrm{mBCl}$ for detection of $\mathrm{GSH}^{79}$. N-ethylmaleimide was prepared as a stock solution in $100 \%$ ethanol and was added to suspensions of cells to a final concentration of $100 \mathrm{mM}$ for $10 \mathrm{~min}$ at room temperature prior to addition of $\mathrm{mBCl}$. Monochlorobimane fluorescence was assessed using a UV laser with excitation wavelength at $360 \mathrm{~nm}$ and an emission at $585 \pm 42 \mathrm{~nm}$ (Fl2) set on a FACS Aria (Becton-Dickinson, USA).

\section{Glutathione peroxidase assay}

For glutathione peroxidase determination, we used the Glutathione Peroxidase Assay Kit (Colorimetric) from abcam and followed the manufacturer's instruction. The data are expressed in enzymatic units per mg protein.

\section{Calcein quenching experiments}

In order to measure calcein quenching, cells were loaded with $0.25 \mu \mathrm{g} / \mathrm{mL}$ calcein-1AM in serum-free media for $30 \mathrm{~min}$ at $37^{\circ} \mathrm{C}$, rinsed, and then treated (in triplicate) as specified in complete culture media for $2 \mathrm{~h}$. The cells were rinsed three times with PBS, and green fluorescence was measured by flow cytometry at $525 \pm 10 \mathrm{nM}$ (FL-1).

\section{Caspase activation, fluorimetric assays}

Isolated Huh-7 cells were washed and suspended in calcium-free buffer solution $(140 \mathrm{mM} \mathrm{NaCl}, 1.13 \mathrm{mM}$ $\mathrm{MgCl}_{2}, 4.7 \mathrm{mM} \mathrm{KCl}, 10 \mathrm{mM}$ glucose, $0.1 \mathrm{M}$ EDTA, and $10 \mathrm{mM}$ HEPES, $\mathrm{pH}$ 7.2). Cells untreated or treated with $20 \mu \mathrm{M}$ curcumin for $24 \mathrm{~h}$ were then loaded at room temperature for $30 \mathrm{~min}$ with fluorescent indicator-linked substrates presented as kits-Vybrant ${ }^{\mathrm{TM}}$ FAM Caspase-3 and -7 Assay Kit - CaspGLOW ${ }^{\mathrm{TM}}$ Fluorescein Active Caspase-9 Staining Kit and the Vybrant FAM caspase-8 assay kit (V35119), all from Molecular Probes, and analyzed by flow cytometry. The percentage of cells (\%) that are viable or in early apoptosis (PI negative or with a slight increase in PI) with caspase activity greater than that of the control was taken into consideration, whereas the cells that were totally permeable to PI were excluded, as were the control cells (negative for PI and almost negative for caspase activity).

\begin{abstract}
Author details
${ }^{1}$ CNRS UMR 8003, SSPIN Saints-Pères Neurosciences Institute, Paris University, Saint-Germain Campus, 45 rue des Saints-Pères, 75006 Paris, France. ${ }^{2}$ INSERM U1148, Laboratory for Vascular Translational Science, UFR SMBH, Université Paris 13, Sorbonne Paris Cité, F-93017 Bobigny, France. ${ }^{3}$ Division of Molecular Medicine, Ruder Boškovic Institute, Bijenička cesta 54, 10000 Zagreb, Croatia. ${ }^{4}$ Medical faculty Bichat, UMR 1149-ERL CNRS 8252-Université Paris Diderot Paris 7, 16 rue Henri Hucherd, F-75890 Paris, France. ${ }^{5}$ Laboratoire Jean Perrin, Université Pierre et Marie Curie-Paris 6, CNRS FRE 3231 Case Courrier 138, 4 place Jussieu, F-75252 Paris cedex 05, France. ${ }^{6}$ Present address: Head of the pharmacology and toxicology department, Faculty of pharmacy Albaath university, Homs, Syria
\end{abstract}

\section{Conflict of interest}

The authors declare that they have no conflict of interest.

\section{Publisher's note}

Springer Nature remains neutral with regard to jurisdictional claims in published maps and institutional affiliations.

The online version of this article (https://doi.org/10.1038/s41420-019-0234-y) contains supplementary material, which is available to authorized users.

Received: 23 September 2019 Revised: 24 October 2019 Accepted: 11 November 2019

Published online: 09 December 2019

\section{References}

1. Eaton, J. W. \& Qian, M. Molecular bases of cellular iron toxicity. Free Radic. Biol. Med 32, 833-840 (2002). [pii].

2. Valko, M., Morris, H. \& Cronin, M. T. Metals, toxicity and oxidative stress. Curr. Med. Chem. 12, 1161-1208 (2005).

3. Haber, F. \& Weiss, J. The catalytic decomposition of hydrogen peroxide by iron salts. Proc. R. Soc. Lond., Sect. A. 147, 332-351 (1934).

4. Stal, P. Iron as a hepatotoxin. Dig. Dis. 13, 205-222 (1995).

5. Stal, P., Hultcrantz, R., Moller, L. \& Eriksson, L. C. The effects of dietary iron on initiation and promotion in chemical hepatocarcinogenesis. Hepatology 21, 521-528 (1995). [pii].

6. Hider, C. R. \& Hoffbrand, V. The role of deferiprone in iron chelation. N. Engl. J. med 379, 2140-2150 (2018).

7. Liu, Z. D. \& Hider, R. C. Design of clinically useful iron(III)-selective chelators. Med. Res. Rev. 22, 26-64 (2002). [pii].

8. Richardson, D. R. \& Lovejoy, D. B. Complexes of gallium(III) and other metal ions and their potential in the treatment of neoplasia. Expert Opin. Investig. Drugs 9, 1257-1270 (2000).

9. Kalinowski, D. S. \& Richardson, D. R. Future of toxicology-iron chelators and differing modes of action and toxicity: the changing face of iron chelation therapy. Chem. Res. Toxicol. 20, 715-720 (2007).

10. Haliwell B. \& Gutterridge, J.M.C. Free radicals in Biology and Medecine. (Clarenton Press, Oxford England, 1989).

11. Stockwell, B. R. et al. Ferroptosis: a regulated cell death nexus linking metabolism, redoxbiology, and disease. Cell 171, 273-285 (2017).

12. Dixon, S. J. et al. Ferroptosis: an iron-dependent form of nonapoptotic cell death. Cell 149, 1060-1072 (2012).

13. Alvarez, S. W. et al. NFS1 undergoes positive selection in lung tumours and protects cells from ferroptosis. Nature 551, 639-643 (2017).

14. Weiland, A. et al. Ferroptosis and its role in diverse brain diseases. Mol. Neurobiol. https://doi.org/10.1007/s12035-018-1403-3 (2018).

15. Dusek, P. et al. Brain iron accumulation in Wilson disease: a post mortem 7 Tesla MRI - histopathological study. Neuropathol. Appl. Neurobiol. 43, 514-532 (2017).

16. Kolnagou, A., Kontoghiorghe, C. N. \& Kontoghiorghes, G. J. New targeted therapies and diagnostic methods for iron overload diseases. Front. Biosci. (Schol Ed). 10, 1-20 (2018).

17. Barnham, K. J., Masters, C. L. \& Bush, A. I. Neurodegenerative diseases and oxidative stress. Nat. Rev. Drug Disco. 3, 205-214 (2004). 
18. Wong, A. et al. The Friedreich's ataxia mutation confers cellular sensitivity to oxidant stress which is rescued by chelators of iron and calcium and inhibitors of apoptosis. Hum. Mol. Genet 8, 425-430 (1999).

19. Shinar, E. \& Rachmilewitz, E. A. Oxidative denaturation of red blood cells in thalassemia. Semin Hematol. 27, 70-82 (1990).

20. Ramirez, R. L., Qian, J., Santambrogio, P., Levi, S. \& Koeppen, A. H. Relation of cytosolic iron excess to cardiomyopathy of Friedreich's ataxia. Am. J. Cardiol. 110, 1820-1827 (2012).

21. Boddaert, $\mathrm{N}$. et al. Selective iron chelation in Friedreich ataxia: biologic and clinical implications. Blood 110, 401-408 (2007).

22. Kalinowski, D. S. \& Richardson, D. R. The evolution of iron chelators for the treatment of iron overload disease and cancer. Pharm. Rev. 57, 547-583 (2005).

23. Yu, Y., Wong, J., Lovejoy, D. B., Kalinowski, D. S. \& Richardson, D. R. Chelators at the cancer coalface: desferrioxamine to Triapine and beyond. Clin. Cancer Res. 12, 6876-6883 (2006).

24. Kolberg, M., Strand, K. R., Graff, P. \& Andersson, K. K. Structure, function, and mechanism of ribonucleotide reductases. Biochim Biophys. Acta 1699, 1-34 (2004).

25. Thelander, L. \& Graslund, A. Mechanism of inhibition of mammalian ribonucleotide reductase by the iron chelate of 1-formylisoquinoline thiosemicarbazone. Destruction of the tyrosine free radical of the enzyme in an oxygen-requiring reaction. J. Biol. Chem. 258, $4063-4066$ (1983).

26. Thelander, L., Graslund, A. \& Thelander, M. Continual presence of oxygen and iron required for mammalian ribonucleotide reduction: possible regulation mechanism. Biochem Biophys. Res. Commun. 110, 859-865 (1983).

27. Nurtjahja-Tjendraputra, E., Fu, D., Phang, J. M. \& Richardson, D. R. Iron chelation regulates cyclin D1 expression via the proteasome: a link to iron deficiencymediated growth suppression. Blood 109, 4045-4054 (2007).

28. Gao, J. \& Richardson, D. R. The potential of iron chelators of the pyridoxal isonicotinoyl hydrazone class as effective antiproliferative agents, IV: the mechanisms involved in inhibiting cell-cycle progression. Blood 98, 842-850 (2001).

29. Messner, D. J. \& Kowdley, K. V. Neoplastic transformation of rat liver epithelial cells is enhanced by non-transferrin-bound iron. BMC Gastroenterol. 8, 2 (2008). [pii] 10.1186/1471-230X-8-2.

30. Aggarwal, B. B., Sundaram, C., Malani, N. \& Ichikawa, H. Curcumin: the Indian solid gold. Adv. Exp. Med Biol. 595, 1-75 (2007).

31. Rahmani, A. H., Al Zohairy, M. A., Aly, S. M. \& Khan, M. A. Curcumin: a potential candidate in prevention of cancer via modulation of molecular pathways. Biomed. Res Int 2014, 761608 (2014).

32. Anand, P. et al. Biological activities of curcumin and its analogues (Congeners) made by man and Mother Nature. Biochem Pharm. 76, 1590-1611 (2008).

33. Gupta, S. C., Patchva, S. \& Aggarwal, B. B. Therapeutic roles of curcumin: lessons learned from clinical trials. AAPS J. 15, 195-218 (2013).

34. Quiles, J. L. et al. Curcuma longa extract supplementation reduces oxidative stress and attenuates aortic fatty streak development in rabbits. Arterioscler Thromb. Vasc. Biol. 22, 1225-1231 (2002).

35. Ramirez-Tortosa, M. C. et al. Curcumin ameliorates rabbits's steatohepatitis via respiratory chain, oxidative stress, and TNF-alpha. Free Radic. Biol. Med 47, 924-931 (2009).

36. Patil, R. et al. Curcumin targeted, polymalic acid-based MRI contrast agent for the detection of abeta plaques in Alzheimer's disease. Macromol. Biosci. 15, 1212-1217 (2015).

37. Liu, Z. J. et al. Curcumin attenuates beta-amyloid-induced neuroinflammation via activation of peroxisome proliferator-activated receptor-gamma function in a rat model of Alzheimer's disease. Front Pharm. 7, 261 (2016).

38. Mythri, R. B., Jagatha, B., Pradhan, N., Andersen, J. \& Bharath, M. M. Mitochondrial complex I inhibition in Parkinson's disease: how can curcumin protect mitochondria? Antioxid. Redox Signal 9, 399-408 (2007).

39. Mythri, R. B. \& Bharath, M. M. Curcumin: a potential neuroprotective agent in Parkinson's disease. Curr. Pharm. Des. 18, 91-99 (2012).

40. Tejada, S. et al. Wound healing effect of curcumin: a short review. Curr. Pharm. Biotechnol. 17, 1002-7 (2016).

41. Cheppudira, B. et al. Curcumin: a novel therapeutic for burn pain and wound healing. Expert Opin. Investig. Drugs 22, 1295-1303 (2013).

42. Akbik, D., Ghadiri, M., Chrzanowski, W. \& Rohanizadeh, R. Curcumin as a wound healing agent. Life Sci. 116, 1-7 (2014).

43. Kim, J. Y. et al. Curcumin-induced autophagy contributes to the decreased survival of oral cancer cells. Arch. Oral. Biol. 57, 1018-1025 (2012).

44. Moustapha, A. et al. Curcumin induces crosstalk between autophagy and apoptosis mediated by calcium release from the endoplasmic reticulum, lysosomal destabilization and mitochondrial events. Cell Death Disco. 1, 15017 (2015).

45. Li, B. et al. Curcumin induces cross-regulation between autophagy and apoptosis in uterine leiomyosarcoma cells. Int J. Gynecol. Cancer 23, 803-808 (2013).

46. Guo, S. et al. Curcumin activates autophagy and attenuates oxidative damage in EA.hy926 cells via the Akt/mTOR pathway. Mol. Med. Rep. 13, 2187-2193 (2016).

47. Rainey, N., Motte, L., Aggarwal, B. B. \& Petit, P. X. Curcumin hormesis mediates a cross-talk between autophagy and cell death. Cell Death Dis. 6. e2003 (2015).

48. Zhao, G. et al. Curcumin induces autophagy, inhibits proliferation and invasion by downregulating AKT/mTOR signaling pathway in human melanoma cells. Oncol. Rep. 35, 1065-1074 (2016).

49. Guan, F. et al. Curcumin suppresses proliferation and migration of MDA-MB231 breast cancer cells through autophagy-dependent Akt degradation. PLoS ONE 11, e0146553 (2016).

50. Jiao, Y. et al. Iron chelation in the biological activity of curcumin. Free Radic Biol. Med 40, 1152-1160 (2006).

51. Jiao, Y. et al. Curcumin, a cancer chemopreventive and chemotherapeutic agent, is a biologically active iron chelator. Blood 113, 462-469 (2009).

52. Messner, D. J., Sivam, G. \& Kowdley, K. V. Curcumin reduces the toxic effects of iron loading in rat liver epithelial cells. Liver Int 29, 63-72 (2009).

53. Minear, S. et al. Curcumin inhibits growth of Saccharomyces cerevisiae through iron chelation. Eukaryot. Cell 10, 1574-1581 (2011).

54. Baum, L. \& Ng, A. Curcumin interaction with copper and iron suggests one possible mechanism of action in Alzheimer's disease animal models. J. Alzheimers Dis. 6, 367-377 (2004).

55. Priyadarsini, K. I. The chemistry of curcumin: from extraction to therapeutic agent. Molecules 19, 20091-20112 (2014).

56. Jaruga, E., Sokal, A., Chrul, S. \& Bartosz, G. Apoptosis-independent alterations in membrane dynamics induced by curcumin. Exp. Cell Res. 245, 303-312 (1998).

57. Hsing, A. W. et al. Cancer risk following primary hemochromatosis: a population-based cohort study in Denmark. Int J. Cancer 60, 160-162 (1995).

58. Deugnier, Y. \& Turlin, B. Iron and hepatocellular carcinoma. J. Gastroenterol. Hepatol. 16, 491-494 (2001).

59. Kowdley, K. V. Iron, hemochromatosis, and hepatocellular carcinoma. Gastroenterology 127, S79-S86 (2004).

60. Deshpande, S. S. et al. Subchronic oral toxicity of turmeric and ethanolic turmeric extract in female mice and rats. Toxicol. Lett. 95, 183-193 (1998).

61. Soni, K. B., Lahiri, M., Chackradeo, P., Bhide, S. V. \& Kuttan, R. Protective effect of food additives on aflatoxin-induced mutagenicity and hepatocarcinogenicity. Cancer Lett. 115, 129-133 (1997).

62. Chuang, S. E. et al. Curcumin-containing diet inhibits diethylnitrosamineinduced murine hepatocarcinogenesis. Carcinogenesis 21, 331-335 (2000).

63. Barnabé-Pineda, M., Ramírez-Silva, M. T., Romero-Romo, M. A., GonzalezVergara, E. \& Rijas-Hernandez, A. Spectriphotometric and electrochemical determination of teh formation constants of the complexe Curcumin-Fe (III)-water and Curcumin-Fe(II)-water. Spectrochimica Acta 60, 1105-1113 (2004).

64. Zhou, W., Merrick, B. A., Khaledi, M. G. \& Tomer, K. B. Detection and sequencing of phosphopeptides affinity bound to immobilized metal ion beads by matrix-assisted laser desorption/ionization mass spectrometry. J. Am. Soc. Mass Spectrom. 11, 273-282 (2000). [pii].

65. Conrad, M. et al. Regulation of lipid peroxidation and ferroptosis in diverse species. Genes Dev. 32, 602-619 (2018).

66. Maeda, S., Kamata, H., Luo, J. L., Leffert, H. \& Karin, M. IKKbeta couples hepatocyte death to cytokine-driven compensatory proliferation that promotes chemical hepatocarcinogenesis. Cell 121, 977-990 (2005).

67. Bernabe-Pineda, M., Ramirez-Silva, M. T., Romero-Romo, M. A., Gonzalez-Vergara, E. \& Rojas-Hernandez, A. Spectrophotometric and electrochemical determination of the formation constants of the complexes Curcumin-Fe(III)water and Curcumin-Fe(II)-water. Spectrochim. Acta A Mol. Biomol. Spectrosc. 60, 1105-1113 (2004)

68. Martell A. E. \& R.M., S. Critical Stability Constants. New York edn, (Plenum Press, 1977)

69. Messner, D. J., Robinson, T. \& Kowdley, K. V. Curcumin and turmeric modulate the tumor-promoting effects of iron in vitro. Nutr. Cancer 69, 481-489 (2017).

70. Galluzzi, L. et al. Autophagy in malignant transformation and cancer progression. EMBO J. 34, 856-880 (2015) 
71. Nakano, K. et al. Induction of apoptosis by beta-diketones in human tumor cells. Anticancer Res 24, 711-717 (2004).

72. Thompson, K. H. et al. Complementary inhibition of synoviocyte, smooth muscle cell or mouse lymphoma cell proliferation by a vanadyl curcumin complex compared to curcumin alone. J. Inorg. Biochem 98, 2063-2070 (2004).

73. Dutta, S., Murugkar, A., Gandhe, N. \& Padhye, S. Enhanced antioxidant activities of metal conjugates of Curcumin derivatives. Met.-Based Drugs 8, 183-188 (2001).

74. Zhang, S., Tu, C., Wang \& X. Novel cytotoxic copper(II) complexes of 8-aminoquinoline derivatives: crystal structure and different reactivity towards glutathione. Eur. J. Chem. 98, 4028-4035 (2004).

75. Lee, J. S. et al. A novel prognostic subtype of human hepatocellular carcinoma derived from hepatic progenitor cells. Nat. Med. 12, 410-416 (2006).
76. Sureau, F. et al. Microspectrofluorimetric study of the kinetics of cellular uptake and metabolization of benzo(a)pyrene in human T 47D mammary tumor cells: evidence for cytochrome P1450 induction. Eur. Biophys. J. 18, 301-307 (1990).

77. Zamzami, N. et al. Sequential reduction of mitochondrial transmembrane potential and generation of reactive oxygen species in early programmed cell death. J. Exp. Med. 182, 367-377 (1995).

78. Gendron, M. C. et al. Oxidation of pyridine nucleotides during Fas- and ceramide-induced apoptosis in Jurkat cells: correlation with changes in mitochondria, glutathione depletion, intracellular acidification and caspase 3 activation. Biochem J. 353, 357-367 (2001).

79. Hedley, D. W. \& Chow, S. Evaluation of methods for measuring cellular glutathione content using flow cytometry. Cytometry 15, 349-358 (1994). 